\title{
Astigmatic Peripheral Defocus with Different Contact Lenses: Review and Meta-Analysis
}

\author{
António Queirós 이, Daniela Lopes-Ferreira, and José Manuel González-Méijome (1) \\ Clinical \& Experimental Optometry Research Lab, Center of Physics, University of Minho, Braga, Portugal
}

\begin{abstract}
Purpose: To review the level of relative peripheral defocus measured with different devices with potential use for myopia retention. To present comparative data of the change in astigmatic peripheral refraction with different contact lenses evaluated in different studies conducted in the same laboratory following the same methodology in myopic human eyes

Methods: A joint analysis of work, carried out at the same laboratory (CEORLab) in 137 myopic subjects with different types of contact lenses $(C L)$, was performed to obtain the tangential $\left(F_{T}=M-J 0\right)$, sagittal $\left(F_{S}=M+J 0\right)$, and mean $(M)$ power refractive errors (M and J0 are the refraction vector components). Orthokeratology, standard aspheric rigid gas-permeable (RGP), experimental RGP, experimental soft $C L$, and different multifocal soft $\mathrm{CL}$ were used to induce peripheral myopic defocus (236 peripheral refraction measures).

Results: Compared with values obtained in naked eye condition (baseline), only three of the eight approaches tested show statistically significant peripheral myopic defocus induction $(p<0.001)$ in both temporal and nasal retina (orthokeratology, experimental RGP, and Proclear multifocal CL with Add: +3.00 D). Standard aspheric RGP also produced a significant increase in myopic defocus for the $F_{T}$, of about $-2.00 \mathrm{D}$. The experimental soft $\mathrm{CL}$, designed to mimic the peripheral performance of the experimental RGP, induced a similar effect to the standard aspheric soft CL.

Conclusion: Orthokeratology, multifocal soft $\mathrm{CL}$, and custom-designed RGP $\mathrm{CL}$ were able to generate a significant relative peripheral myopia in myopic eyes. Conversely, standard and experimental soft $\mathrm{CL}$ were not able to induce significant peripheral myopic and astigmatic defocus values.
\end{abstract}

\section{ARTICLE HISTORY}

Received 20 March 2015

Revised 30 October 2015

Accepted 1 November 2015

\section{KEYWORDS}

Astigmatism; myopia

progression; peripheral

defocus; peripheral

refraction

\section{Introduction}

Peripheral refraction has been widely studied since it was suggested that it might play a role in the refractive development of the eye, more specifically in myopia progression. ${ }^{1,2}$ Previous animal studies reported that peripheral hyperopic defocus (light focused "behind" the retina) seems to act as a stimulus for central myopic development. ${ }^{3}$ It has been observed that peripheral refraction is relatively more hyperopic in myopic eyes than in emmetropic along the horizontal visual field. ${ }^{4}$ There is also evidence of differences in peripheral refraction between Asian and Caucasian eyes ${ }^{5}$ and between progressing and stable myopes. ${ }^{6}$

However, there is controversy over the potential benefit of manipulating peripheral defocus to interfere with the emmetropization mechanism of the eye. This is because the relative peripheral hyperopia appears to exert little consistent influence on the risk of the onset of myopic refractive error, on the rate of myopia progression, or on axial elongation in children ${ }^{7}$, as observed in other clinical studies. ${ }^{8,9}$ While a previous report had assigned a supplementary risk of onset of myopia to adult subjects who manifested hyperopic peripheral refraction, ${ }^{10}$ others suggested that hyperopic blur is a risk factor for myopia progression only when the eye has a negative spherical aberration, because that is the combination leading to relatively low contrast in the defocused retinal image. ${ }^{11}$ Despite this it is not well understood how the eye distinguishes signs of defocus. A potential explanation could be the use of the relative position of both astigmatic focal surfaces (sagittal and tangential), as previously suggested by Howland and further elaborated upon by Charman. ${ }^{12}$ According to this theory, Howard Holland has suggested that the retinal circuitry involving cells sensitive to different orientations might be involved in detecting the relative position of the tangential and sagittal image planes. The peripheral retina is less likely to be involved in defocus sensitivity due to its lack of resolution. However, it is argued that it might be much more sensitive to radially and tangentially oriented gratings. ${ }^{12}$ The mechanisms by which the eventual detection of the stimulus results in an action to elongate or not to elongate the eyeball are still elusive. Several treatments addressing changes in the peripheral refraction issue are now available. ${ }^{13,14}$ Some of these treatments were specifically designed for the purpose of inducing peripheral myopic defocus, while others that are commercially available to correct central myopia and presbyopia also shown successful results in preventing myopia progression. ${ }^{15,16}$

CONTACT Antonio Queirós aqp@fisica.uminho.pt Department of Physics (Optometry), School of Science, University of Minho, CEORLab, Gualtar, Braga, 4710-057, Portugal.

(c) 2016 Taylor \& Francis 
Single-vision (SV) soft contact lenses (SCLs) have been reported to potentially change the state of relative peripheral defocus. However, Shen et al. study revealed that visual correction with SVCLs did not provide significant change in relative peripheral hyperopia, although could be expected to slightly decrease in peripheral hyperopia with both soft and rigid CLs. ${ }^{17}$ On the other hand, another study showed that full correction of central myopia with Proclear SCLs resulted in an increase in relative peripheral hyperopia in both low and moderate myopes. Opposite reports were related with differences in design of each specific SV SCL studied. ${ }^{18}$

Orthokeratology $(\mathrm{OK})$ is considered a corrective treatment that also allows myopia retention. ${ }^{19}$ Previous studies on OK observed retention rates of about $40 \%$ in children of different ethnicities. ${ }^{20-22}$ Also, aspheric center-distance multifocal contact lenses (MFCLs) demonstrated retention rates of about 40-50\% in recent clinical trials ${ }^{23}$ and also axial elongation reduction of $20 \%$, after 2 years. Both treatments have in common the production of a relative peripheral myopia reversely comparing with baseline condition in which could be seen a relative hyperopia. After OK, the expected relative myopia induced is correlated 1:1 with central myopia ${ }^{24,25}$, being almost symmetrical across horizontal and vertical meridians of the peripheral retina. ${ }^{26}$

Center-distance MFCL predictably induces peripheral myopia, ${ }^{27,28}$ which might be expected knowing that increasing the additional power of MFCL also increases the induction of peripheral myopia. A study has shown that center-distance aspheric multifocal soft contact lenses with +3.00 and +4.00 add power induced more peripheral myopia than +1.00 and $+2.00 \mathrm{D}$ add lenses. However, there were no differences between +3.00 and +4.00 and the off-axis myopia induced was less symmetric between nasal and temporal retina with the higher add powers. ${ }^{27}$

Recently, Flitcroft highlighted the impact of different corneal and retinal shapes on the relative position of the sagittal and tangential image shells. ${ }^{29}$ Our results indeed suggested that this pattern is significantly different between progressing and stable myopes in a cross sectional study involving 60 ethnic, age, foveal refraction, and axial length-matched stable and progressive myopes. ${ }^{6}$

Some earlier attempts to measure peripheral refraction were performed in the context of studies evaluating night vision and night myopia, with the justification that vision at very low brightness involves the parafoveal area up to $10-15^{\circ}$. As early as 1918, Ogata and Weymouth measured refraction at various angles and found that $40 \%$ of the sample measured showed increasing relative peripheral myopia until $4^{\circ}$ of eccentricity, where the value became constant at about $-0.37 \mathrm{D}(-0.30$ to $-0.50 \mathrm{D})$. They justified this finding with the parafoveal cupping of the retina. ${ }^{30}$ The importance of the pattern of astigmatic refraction was originally attributed to the early works of Ferree and his definition of different patterns and their role in emmetropization (1931-33). ${ }^{31}$ Ames and Proctor, in a review paper published in 1921, reported that the retina is located between the primary (tangential) and secondary (sagittal) foci. ${ }^{32}$ Results from animal studies provided evidence of a significant correlation effect between the relative astigmatic defocus (sagittal and tangential power errors) and the emmetropization process of rhesus monkeys. ${ }^{33}$ Despite this, most previous studies addressing the changes in peripheral refraction concentrated on spherical equivalent changes and vectorial decomposition of astigmatism ( $J 0$ and J45). Table 1 shows the outcomes of different studies reporting the changes in relative peripheral defocus with different contact lenses. ${ }^{14,17,18,24,26-28,34-39}$ Conversely, information about the relative position of the sagittal and tangential components of refraction regarding the retinal plane across the visual field is lacking in the literature published on this topic. Therefore this study looks at peripheral refraction in the tangential and sagittal planes.

The goal of the present study is to report aggregated data showing the changes induced by different contact lenses on peripheral astigmatic defocus. With this work we intend to summarize the results of different studies and provide a comparative view of all the results obtained from the same center with the same methodology using different optical devices.

\section{Methods}

\section{Subjects and lenses}

The present study gather the results of different clinical trials conducted at the Clinical and Experimental Optometry Research Lab (CEORLab, Minho University, Braga, Portugal) between January 2008 and December 2012. The results of those studies, comprising a total of 137 eyes, are published in previous works (see Table 2). ${ }^{24,28,40-42}$ However, the information provided here has not previously been reported.

A total of eight different contact lens types tested in 137 subjects resulted in 236 peripheral refraction measures. Those included orthokeratology ${ }^{24}(n=28)$, standard aspheric rigid gaspermeable (RGP, $n=52),{ }^{41}$ experimental RGP $(n=52)^{41}$, and experimental soft CL $(n=10)^{40}$ to facilitate induction of peripheral myopic defocus, concentric MFCL (Oasys, $n=19),{ }^{42}$ aspheric center-distance silicone hydrogel soft MFCL with Add: +2.00 $\mathrm{D}$ (Biofinity multifocal D, $n=19)^{42}$ and aspheric center-distance MFCL with add: $+2.00 \mathrm{D}$ (Proclear Multifocal $\mathrm{D}, n=28{ }^{28}$, and $+3.00 \mathrm{D}$ (Proclear multifocal D, $n=28$ ). ${ }^{28}$ Table 2 summarizes the characteristics of all the contact lenses involved in the experiments reported.

With the exception of orthokeratology, all the remaining studies were non-dispensing. All studies included a young Caucasian university student population with the same inclusion and exclusion criteria. In brief, subjects were required to have myopia, without any eye disease or injury, no previous history of refractive surgery, and not being under the effect of any ocular or systemic medication. Table 3 summarizes the demographic data for the different samples evaluated for each treatment. As defined in the respective publications, the participants were fully informed about the purpose, all the procedures of each study were approved by the Scientific Committee of the School of Sciences of Minho University (Portugal), and all participants gave their written agreement following the tenets of the Declaration of Helsinki Research protocol. The data obtained under naked eye condition 
$\frac{\sqrt{2}}{3}$

西

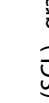

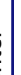

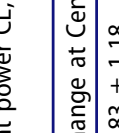

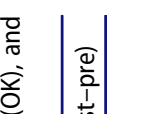

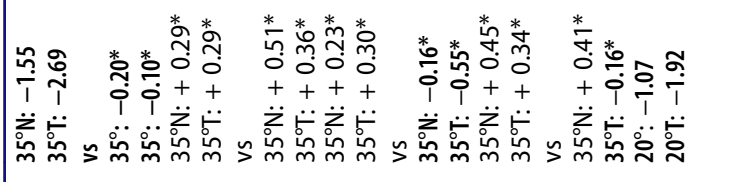

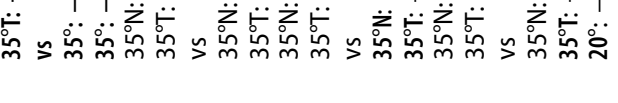

市

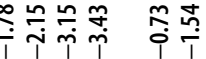

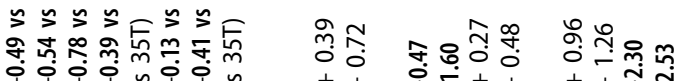

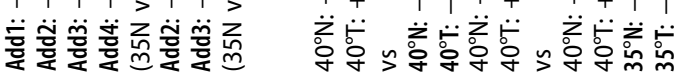

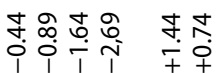

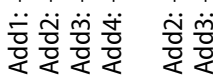

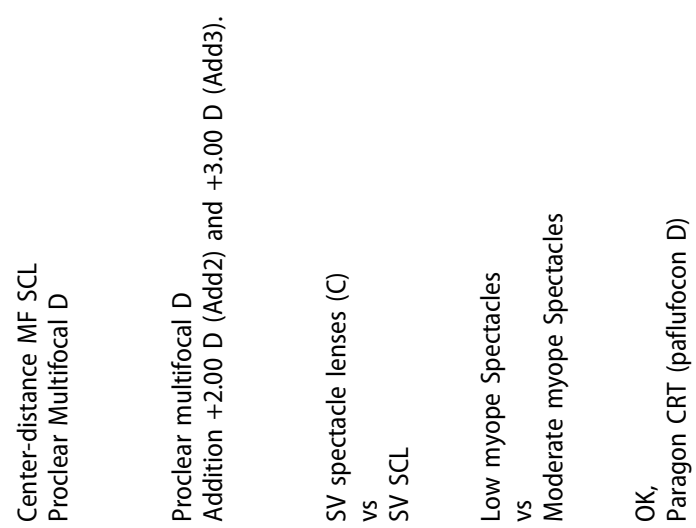

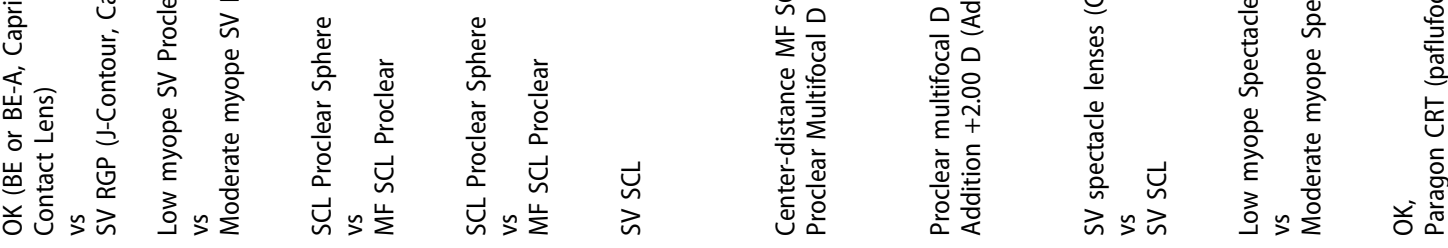

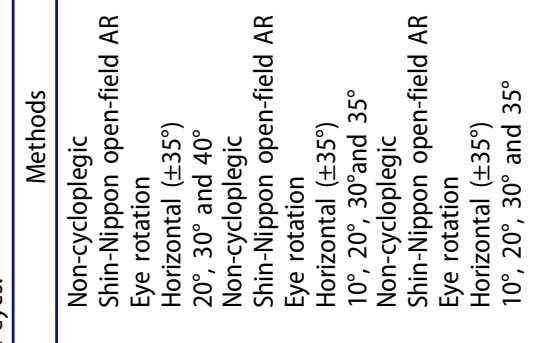

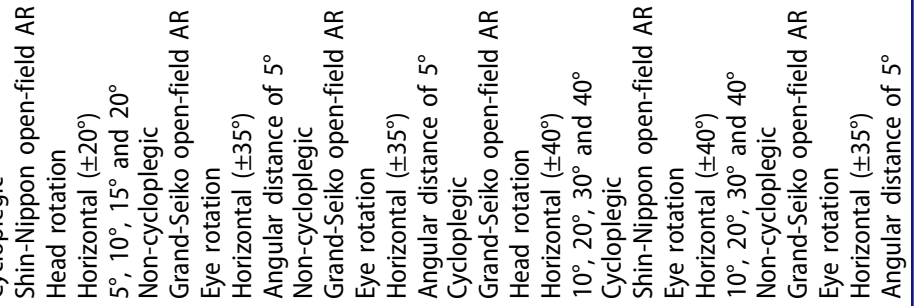

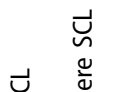

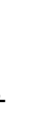

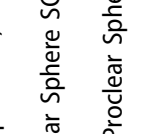
는

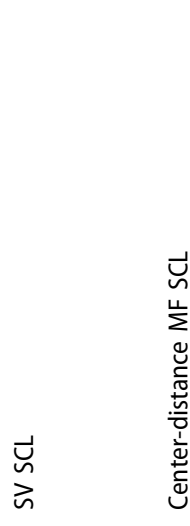




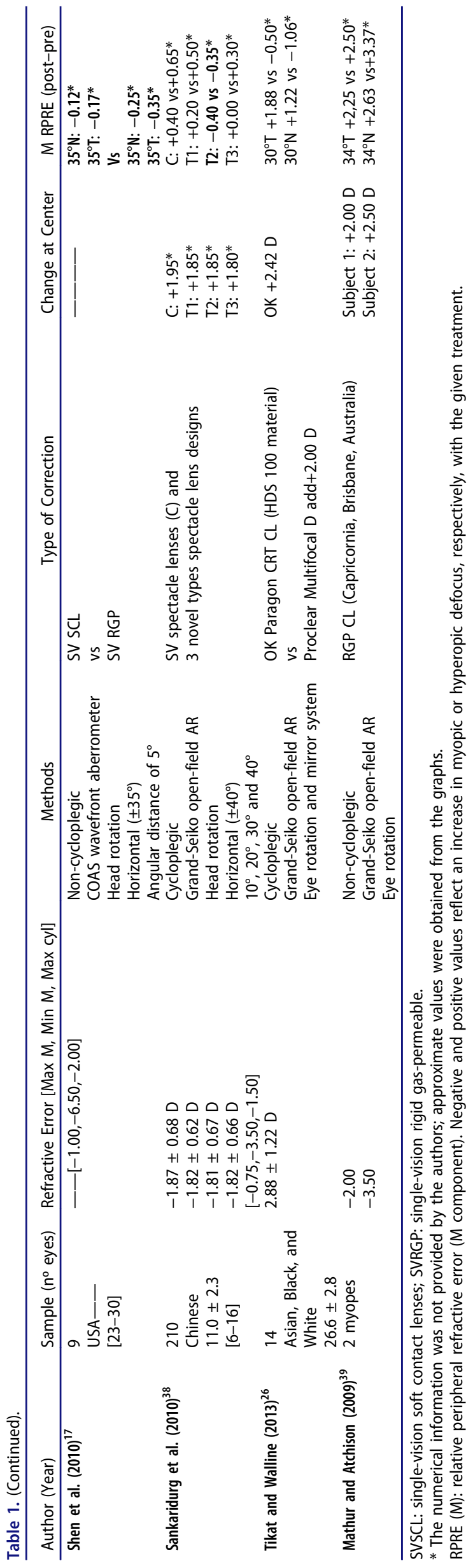


Table 2. Characteristics of the contact lenses used in the studies reported.

\begin{tabular}{|c|c|c|c|c|c|c|c|}
\hline $\begin{array}{l}\text { Type of } \\
\text { contact lens }\end{array}$ & Ortho-K & Center-distan & ce Multifocal & Concentric Multifocal & $\begin{array}{l}\text { Experimental } \\
\text { Soft } C L\end{array}$ & Aspheric RGP & $\begin{array}{l}\text { Experimental } \\
\text { RGP }\end{array}$ \\
\hline Previous Report & Queiros et al. $2010^{24}$ & $\begin{array}{l}\text { Lopes-Ferreira et al. } \\
2013^{28}\end{array}$ & $\begin{array}{l}\text { Lopes-Ferreira et al. } \\
2015^{42}\end{array}$ & $\begin{array}{l}\text { Lopes-Ferreira et al. } \\
2015^{42}\end{array}$ & $\begin{array}{l}\text { Pauné et al. } \\
2014^{40}\end{array}$ & Pauné et al. $2015^{41}$ & \\
\hline Brand & Paragon CRT & $\begin{array}{l}\text { Proclear Multifocal } \\
\text { D }\end{array}$ & $\begin{array}{l}\text { Biofinity Multifocal } \\
\text { D }\end{array}$ & $\begin{array}{l}\text { Acuvue Oasys for } \\
\text { Presbyopia }\end{array}$ & Amiopik Soft & Aspheric & Amiopik \\
\hline Material & Paflufocon D & Omafilcon A (62\%) & Comfilcon A (48\%) & Senofilcon A (38\%) & $\begin{array}{l}\text { Polymacon } \\
(38 \%)\end{array}$ & Boston EO & Boston EO \\
\hline Dk & & 27 & 128 & 103 & & & \\
\hline Base Curve & variable & 8.6 & 8.6 & 8.4 & 8.7 & variable & variable \\
\hline Overall Diameter & 10.5 & 14.4 & 14.4 & 14.3 & 10.5 & 10.8 & 10.8 \\
\hline Optic Zone & 6.0 & 8.7 & 8.6 & 8.4 & 8 & 8 & 8 \\
\hline Geometry & Ortho-k & $\begin{array}{l}\text { Aspheric Center- } \\
\text { Distance }\end{array}$ & $\begin{array}{l}\text { Aspheric Center- } \\
\text { Distance }\end{array}$ & Multiconcentric & Bicurve & Aspheric & $\begin{array}{l}\text { Center- } \\
\text { Distance }\end{array}$ \\
\hline $\begin{array}{l}\text { Other } \\
\quad \text { specifications }\end{array}$ & $\begin{array}{l}\text { Sigmoid Geometry } \\
\text { Overnight Wear }\end{array}$ & $\begin{array}{l}\text { Add: }+2.00 \mathrm{D} \text { and } \\
+3.00 \mathrm{D}\end{array}$ & Add: $+2.50 \mathrm{D}$ & Add: $+2.50 \mathrm{D}$ & $\begin{array}{l}\text { Add: +1.50@ } \\
30^{\circ}\end{array}$ & $\begin{array}{l}\text { Distance } \\
\text { Correction Only }\end{array}$ & $\begin{array}{l}\text { Add: +1.50@ } \\
30^{\circ}\end{array}$ \\
\hline
\end{tabular}

(baseline) from the same subjects, as peripheral refractive error, were collected and analyzed as baseline data for comparison purposes.

\section{Peripheral refraction measurements}

Objective central and peripheral refraction was measured in the right eye by a non-cycloplegic examination using an openfield autorefractor/keratometer (Grand-Seiko WAM-5500, Grand-Seiko Co., Ltd., Hiroshima, Japan). The illumination in the examination room was adjusted to obtaining sufficiently large pupil size to allow peripheral measurements, which were achieved in all cases without pharmacological midriasis. The left eye was always occluded during measurements. Peripheral refraction was taken at known eccentricities presented in a static target, located at $2.5 \mathrm{~m}$ and consisting of an offset of LEDs arranged on a horizontal flat rail implying eccentricities between $30^{\circ}$ nasal and $30^{\circ}$ temporal, in intermediate $5^{\circ}$ or $10^{\circ}$ steps, depending on the study. As the targets used in studies were small LED lights and were located at 2.5 me distance, the expected accommodative demand would be about 0.5 D. However, measurements at distance using an open-field autorefractor did not significantly change the axial refractive error, in comparison with cycloplegic refractive values, in young subjects. ${ }^{43}$ All measurements reported were obtained by rotating the eye to rectify fixation of the peripheral LED targets. The objective refraction was averaged from five measures taken on- and off-axis, at each retinal eccentricity ( $\alpha$ ). Individual data were converted to vector components according to Fourier analysis, as recommended by Thibos. ${ }^{44}$ $\mathrm{M}, \mathrm{J0}$, and J45 are only presented as descriptive values for the sample characterization. For statistical analysis only the tangential $\left(\mathrm{F}_{\mathrm{T}}=\mathrm{M}+\mathrm{J} 0\right)$ and sagittal $\left(\mathrm{F}_{\mathrm{S}}=\mathrm{M}-\mathrm{J} 0\right)$ power errors were considered. We have previously published data on astigmatic peripheral defocus, decomposed in sagittal and tangential power errors for myopic eyes undergoing orthokeratology treatment $^{45}$

\section{Statistical analysis}

Refraction data were treated statistically using SPSS (for Windows, version 20, New York, USA). The Shapiro-Wilk Test was applied to evaluate the normality of data distribution. When normality could not be assumed, the Wilcoxon signed-rank test was used for paired comparison (between baseline and post-treatment values; nasal and temporal symmetry of the refractive profile; and relative peripheral myopia with eccentricity/center), and paired-sample $t$-testing was used when normality could be assumed. The concept of relative peripheral refractive error (RPRE) was used to define the degree of myopia/hyperopia at baseline or induced by the treatment for each eccentric location, normalized to the axial refraction off-axis minus on-axis. For statistical purposes, $p$-values lower than 0.05 were considered statistically significant.

\section{Results}

Figure 1 shows RPRE (M) as a function of field angle with and without (naked eye) each type of CL in the temporal (T) and nasal $(\mathrm{N})$ retinal area.

\section{Relative peripheral myopia}

The concept of RPRE was used to define the degree of myopia/hyperopia existing or induced by the CL at each eccentric location compared to the axial refraction (at $0^{\circ}$ ). For a given eccentric location of angle $=\alpha, \mathrm{RPRE} \alpha=\mathrm{PRE} \alpha$ (post-CL) RPREa (pre-CL), with $\mathrm{M}$ or $\mathrm{J}_{0}$ as previously defined. This section reports the change in relative peripheral defocus from the center towards the periphery with different optical design devices (CL). We are particularly interested in reporting at which eccentricity $(\alpha)$ the RPRE becomes significantly myopic.

In the $\mathrm{OK}$ treatment the nasal retina becomes significantly myopic beyond $15^{\circ}$ (i.e., $p<0.05$ for $\alpha>20^{\circ}$ ) and in the temporal retina beyond $10^{\circ}$ (i.e., $p<0.05$ for $a>15^{\circ}$ ). Regarding changes in $\mathrm{F}_{\mathrm{T}}$ power error, all points except those located between $15^{\circ}$ nasal and $5^{\circ}$ temporal show statistically significant differences compared to changes in axial refraction, and for the $\mathrm{F}_{\mathrm{S}}$ component all points except the central ones $(\alpha$ $=15^{\circ}$ nasal to $15^{\circ}$ temporal). This follows experimental RGP showing myopic RPRE from $10^{\circ}$ in the nasal retina to $5^{\circ}$ in the temporal retina. The third approach, showing a significant RPRE myopic defocus, is Proclear multifocal with $+3.00 \mathrm{D}$ near add. On the other hand, Acuvue Oasys multifocal presents 


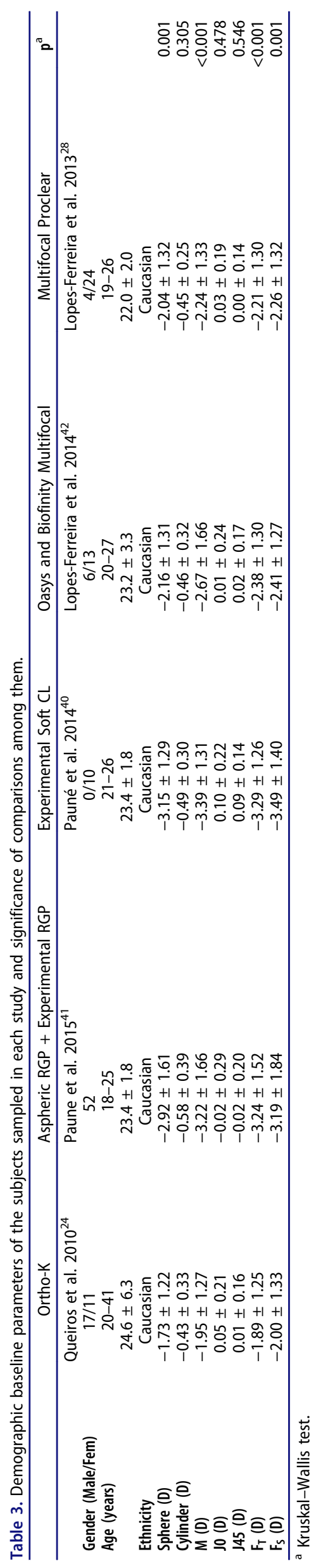



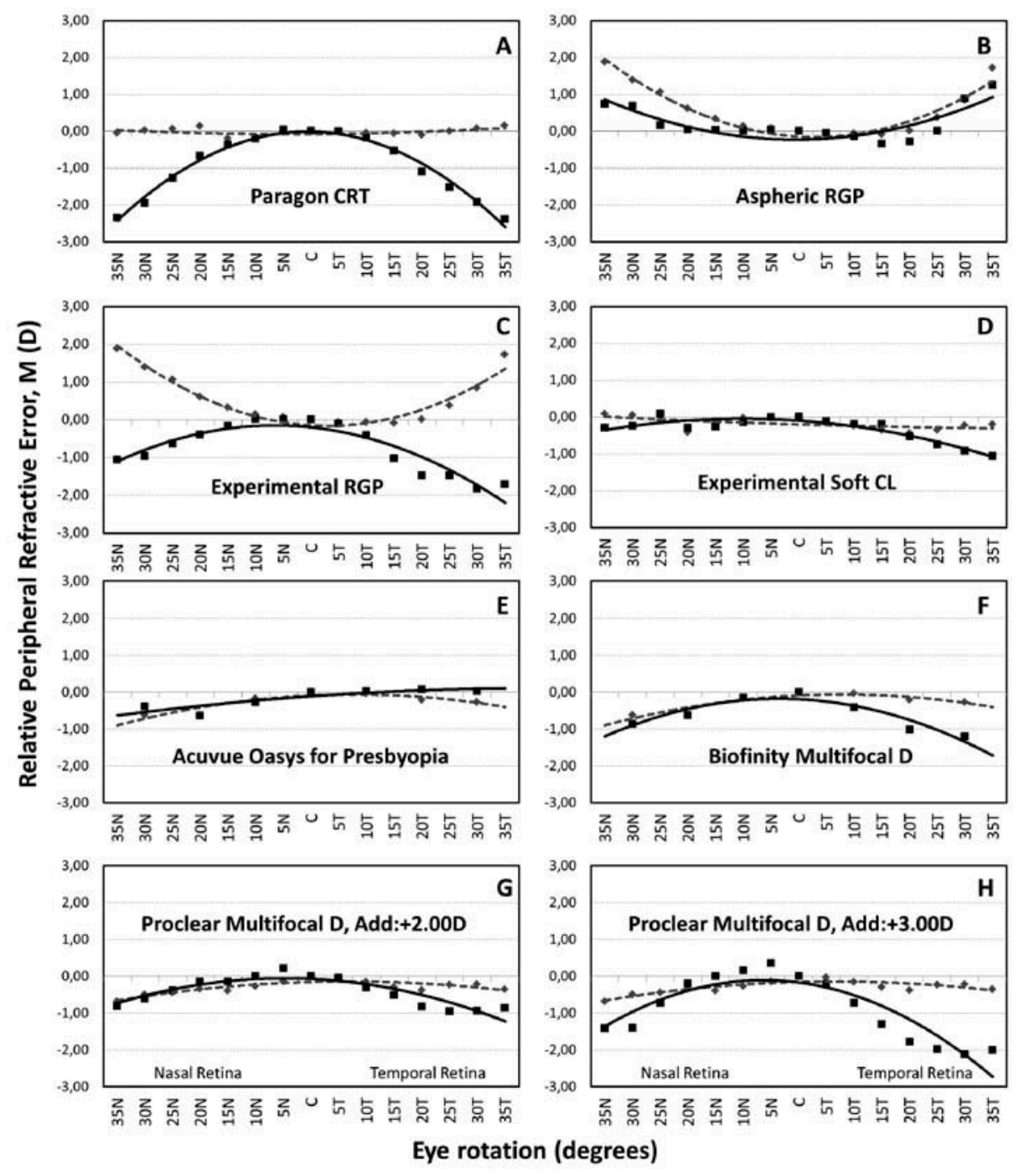

Figure 1. Relative peripheral refractive error $(M)$ as a function of field angle with and without each type of contact lens in the temporal $(T)$ and nasal $(N)$ retinal area. Lines represent second-order polynomial fits to the data from: orthokeratology (A), aspheric RGP (B), experimental RGP (C), experimental soft CL (D), Acuvue Oasys multifocal $(E)$, biofinity multifocal $D(F)$, Proclear multifocal $D$ add: $+2.00 D(G)$, Proclear multifocal $D$ add: $+3.00 D(H)$. Gray dashed line denotes under naked-eye condition (baseline) and black solid line denotes contact lenses.

a "flat" pattern with no significant change in RPRE for peripheral eccentricities ( $p>0.05$, for all eccentricities). Table 4 presents the average values of RPRE for $M, F_{S}$, and $F_{T}$ measured for each treatment at $30^{\circ}$ of eccentricity.

\section{Symmetry of refractive profile vs. eccentricity}

This section reports the symmetry between the relative peripheral defocus, comparing the nasal and temporal areas for each given eccentricity $\left(10^{\circ}, 20^{\circ}, 30^{\circ}\right)$. Figure 2 shows the average peripheral refractive patterns obtained with each treatment. Plots represent relative peripheral defocus, with all curves normalized to set the central refractive value at "zero." This provides an enhanced view of the relative changes in peripheral refraction compared to central measurement. For the $\mathrm{F}_{\mathrm{T}}$ component there were no statistically significant differences between nasal and temporal corresponding eccentricities of the retina for aspheric RGP (B) and experimental sSCL (D); for the $F_{S}$ component there were no statistically significant differences for orthokeratology (A), aspheric RGP (B), and experimental RGP (C). The treatments that induced a more marked increase in myopic RPRE were experimental RGP and orthokeratology lenses. Additionally, orthokeratology was the treatment that produced the least asymmetrical refractive pattern comparing nasal and temporal retina at $30^{\circ}$ eccentricity: difference in $\mathrm{F}_{\mathrm{T}}=0.05 \pm 2.48 \mathrm{D}(p=0.266)$ and difference in $\mathrm{F}_{\mathrm{S}}=0.01 \pm 1.08 \mathrm{D}(p=0.962)$.

\section{Discussion}

The present study provides a meta-analysis of peripheral refraction data obtained from different contact lenses used or with the potential to be used in myopia progression studies. Using the same methodology at the same research center we have shown that their effect on peripheral refraction varies significantly.

Peripheral refraction has become an important issue in the evaluation of myopia progression, as it can provide an explanation for the effectiveness in myopia retention of certain treatments such as orthokeratology. However, it is not well 
Table 4. Relative peripheral difference between center and $30^{\circ}$ eccentricity in the nasal and temporal retina.

\begin{tabular}{|c|c|c|c|c|c|c|}
\hline & \multicolumn{2}{|c|}{$M$} & \multicolumn{2}{|c|}{$\mathrm{F}_{\mathrm{T}}$} & \multicolumn{2}{|c|}{$\mathrm{F}_{\mathrm{S}}$} \\
\hline & Nasal & Temporal & Nasal & Temporal & Nasal & Temporal \\
\hline Paragon $\mathrm{CRT}^{24}$ & $-1.96 \pm 1.86 ; 0.000+$ & $-1.99 \pm 1.34 ; 0.000^{*}$ & $-2.98 \pm 2.63 ; 0.000+$ & $-3.03 \pm 1.89 ; 0.000^{*}$ & $-0.94 \pm 1.19 ; 0.000^{*}$ & $-0.95 \pm 0.95 ; 0.000^{*}$ \\
\hline Aspheric $\mathrm{RGP}^{41}$ & $-0.71 \pm 2.12 ; 0.001+$ & $0.05 \pm 2.84 ; 0.410+$ & $-1.05 \pm 2.79 ; 0.009^{*}$ & $-0.17 \pm 3.99 ; 0.759^{*}$ & $-0.37 \pm 1.64 ; 0.003+$ & $0.26 \pm 2.02 ; 0.917+$ \\
\hline Experimental RGP $\mathrm{P}^{41}$ & $-2.36 \pm 1.95 ; 0.000^{*}$ & $-2.67 \pm 1.81 ; 0.000^{*}$ & $-3.46 \pm 2.85 ; 0.000^{*}$ & $-4.02 \pm 3.07 ; 0.000^{*}$ & $-1.25 \pm 1.26 ; 0.000+$ & $-1.32 \pm 0.85 ; 0.000^{*}$ \\
\hline Experimental Soft $\mathrm{CL}^{40}$ & $-0.29 \pm 0.53 ; 0.121^{*}$ & $-0.69 \pm 0.46 ; 0.001^{*}$ & $-0.56 \pm 0.75 ; 0.043^{*}$ & $-0.88 \pm 0.70 ; 0.003^{*}$ & $-0.02 \pm 0.66 ; 0.944^{*}$ & $-0.50 \pm 0.55 ; 0.018^{*}$ \\
\hline $\begin{array}{l}\text { Acuvue Oasys for } \\
\text { Presbyopia }{ }^{42}\end{array}$ & $0.23 \pm 0.63 ; 0.133^{*}$ & $0.31 \pm 0.72 ; 0.091^{*}$ & $0.33 \pm 0.84 ; 0.114^{*}$ & $0.15 \pm 0.83 ; 0.444^{*}$ & $0.14 \pm 0.66 ; 0.382^{*}$ & $0.46 \pm 0.86 ; 0.039^{*}$ \\
\hline Biofinity Multifocal $\mathrm{D}^{42}$ & $-0.25 \pm 0.69 ; 0.149^{*}$ & $-0.93 \pm 0.58 ; 0.000^{*}$ & $-0.50 \pm 0.84 ; 0.022^{*}$ & $-1.05 \pm 0.62 ; 0.000^{*}$ & $0.01 \pm 0.62 ; 0.958^{*}$ & $-0.80 \pm 0.66 ; 0.000^{*}$ \\
\hline $\begin{array}{l}\text { Proclear Multifocal D } \\
2.00 \mathrm{D}^{28}\end{array}$ & $-0.11 \pm 0.75 ; 0.442^{*}$ & $-0.72 \pm 1.00 ; 0.000+$ & $-0.04 \pm 1.08 ; 0.856^{*}$ & $-0.98 \pm 1.42 ; 0.000+$ & $-0.18 \pm 0.56 ; 0.092^{*}$ & $-0.46 \pm 0.77 ; 0.003+$ \\
\hline $\begin{array}{l}\text { Proclear Multifocal D } \\
\quad 3.00 D^{28}\end{array}$ & $-0.90 \pm 0.96 ; 0.000^{*}$ & $-1.89 \pm 1.34 ; 0.000^{*}$ & $-1.16 \pm 1.21 ; 0.000^{*}$ & $-2.47 \pm 1.85 ; 0.000+$ & $-0.64 \pm 0.88 ; 0.001^{*}$ & $-1.31 \pm 1.10 ; 0.000^{*}$ \\
\hline
\end{tabular}

Bold type denotes statistically significant differences against center.

understood how the eye distinguishes signs of defocus that triggers ocular growth. Several theories have been proposed, one of which is related to the oblique astigmatism of the eye. $^{46,47}$ It has been hypothesized that the ocular growth mechanism in the peripheral retina might use orientation cues to assess the "positions" of the two astigmatic image shells and thus compensate for axial elongation whenever the relative peripheral sagittal focal line "stands behind" the
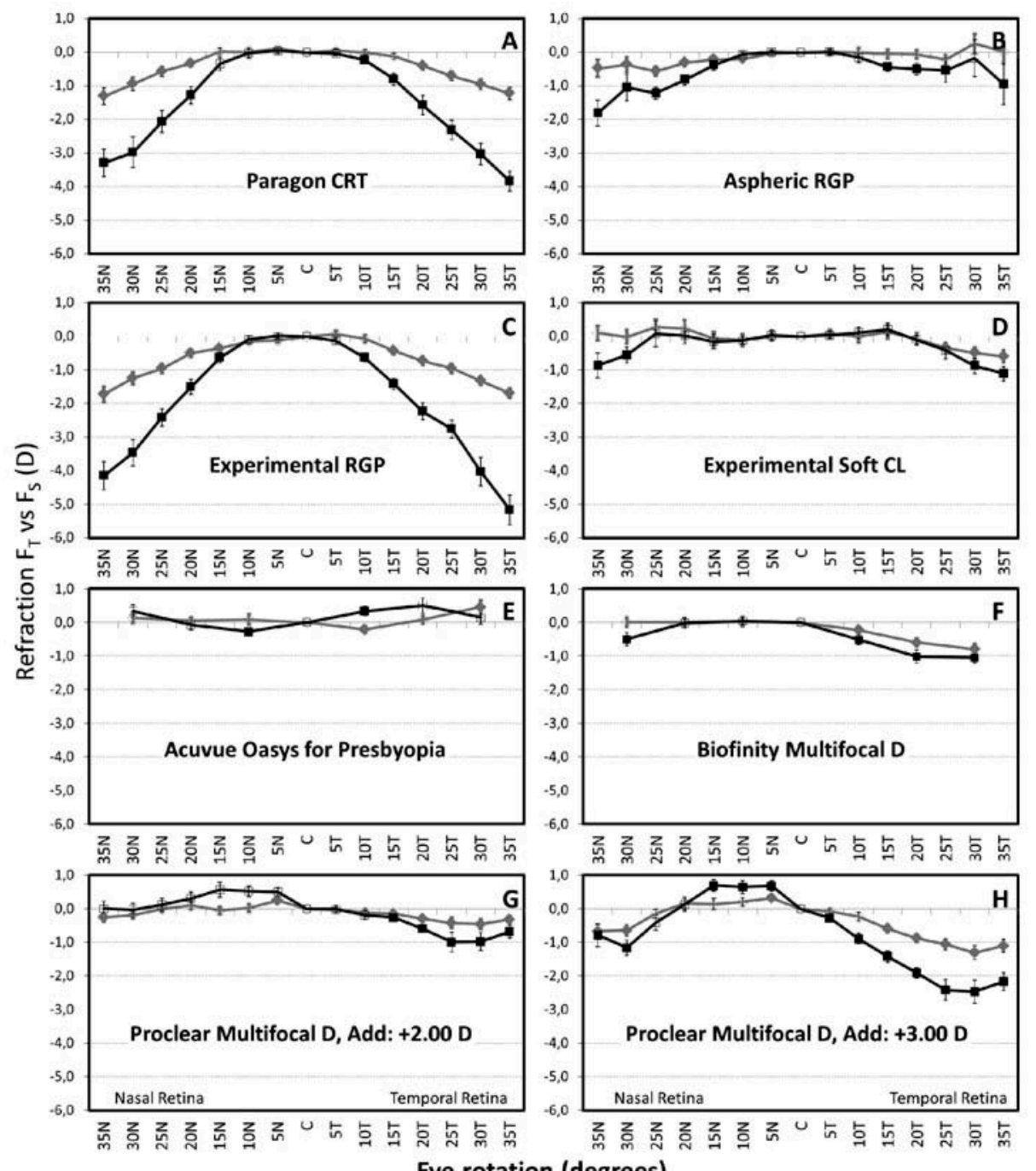

Figure 2. Relative differences (treatment minus baseline) between components refraction $\mathrm{F}_{\mathrm{T}}$ (black line) and $\mathrm{F}_{\mathrm{S}}$ (gray line) as a function of field angle across the nasal $(\mathrm{N})$ and temporal $(\mathrm{T})$ retinal area. The filled squares represent the points where the changes in off-axis refraction are significantly more myopic $(p<0.05)$ than those induced in the central visual axis. Orthokeratology (A), aspheric RGP (B), experimental RGP (C), experimental soft CL (D), Acuvue Oasys multifocal (E), biofinity multifocal D (F), Proclear multifocal D add: $+2.00 \mathrm{D}(\mathrm{G})$, Proclear multifocal D add: $+3.00 \mathrm{D}(\mathrm{H})$. Error bars represent standard error of the mean $(\mathrm{SEM})$. 
retina. In this domain, the limits of Sturm's interval (distance between tangential and sagittal focal lengths) and their orientations might provide the necessary cue to stimulate or slow the growth of the posterior pole of the eyeball. Potential explanations for this mechanism are found in the radial orientation of some photosensitive cells that show preferential orientation, maximizing grating contrast in the periphery. ${ }^{12}$ Nevertheless, the mechanism by which the detection of the relative position of the astigmatic foci, which result in a stimulating or protective effect on ocular growth, is not known. This is partly supported by results from Hung et al. ${ }^{48}$, who found differences in the pattern of eye growth in rhesus monkeys dependent on the relative positions of the tangential and sagittal focal lengths with respect to the retinal plane. In the presence of mixed astigmatism, the primates' eyes tended to grow in order to reposition the retina with the most posterior focal shell position $\left(\mathrm{F}_{\mathrm{S}}\right)^{49}$

When analyzing the data from the eight different optical devices reported in this study, there is evidence that both OK lenses and peripheral gradient RGP lenses are able to provide a greater degree of peripheral myopia induction for both limits of Sturm's interval. Rather, treatments such as concentric MFCL (Acuvue Oasys for Presbyopia) did not show potential in producing peripheral myopic defocus, as observed in Figure $1 \mathrm{E}$, despite previous studies having shown to be partly effective in myopia retention. ${ }^{13,15}$ The results suggest that the effectiveness of myopia regulation with lenses of this type ${ }^{13,15}$ cannot be exclusively assigned to peripheral myopic defocus or peripheral astigmatic defocus and other factors may be involved, including changes in both the accommodative activity of the eye and the focusing properties at the foveal area. ${ }^{50,51}$ Recently, Smith et al. suggested that the efficacy of bifocal concentric addition designs used in myopia progression trials ${ }^{13}$ might be explained by a certain effect of peripheral myopic defocus in addition to other potential mechanisms affecting the foveal vision. Although our methodology does not support such an assumption, we have to recognize that due to the sudden power changes between distance and near zones in these MFCL, measuring methods such as autorefractometry or even aberrometry might not be sensitive enough to detect such a hypothetical peripheral myopic defocus, and it is a limitation of this study. Another limitation of the methodology followed might be in the fixation stimulus used. When looking at a LED source of light, the accuracy of consistency of the response may change over time. However, we consider that this is relatively well-controlled source of error by virtue of averaging the five measurements obtained over a short period of time. Finally, the fact that we used a flat target instead of a curved one creates minor changes in the accommodative demand for the eye of $0.054 \mathrm{D}$ when looking at the peripheral LEDs. However, this source of bias is not relevant for the purposes of the study and might have marginally affected the results presented in Figure 1.

Soft peripheral refractive gradient CLs designed for myopia regulation do not seem to be as effective as their rigid counterparts or orthokeratology in changing the peripheral refractive pattern. Their effect on reduction of peripheral hyperopia is limited and only noticed at the most eccentric retinal locations. This is agreement with the results of a recent 2-year longitudinal study evaluating the efficacy of a soft radial gradient contact lens to control myopia progression. ${ }^{52}$ The authors compared the soft lens against orthokeratology and found a lower myopia retention effect compared with orthokeratology, but a significant effect of retention compared with the SV spectacle lens wearers acting as controls. In fact, SCLs are preferred platforms for this kind of device because of their disposability and immediate comfort, which makes them ideal for children. Good centration and dynamical stabilization is fundamental to obtaining a good and required adjustment of peripheral myopic shift. Previous studies a showed lack of effect on reduction of relative peripheral hyperopia at one side of the retina, presumably because the lens was decentered from the visual axis. ${ }^{14}$ Sankaridurg et al. showed that a specially designed MFCL was able to reduce myopia progression by about $30 \% .{ }^{14}$ It seems that the induction of myopic defocus in both the nasal and temporal visual fields could improve the efficacy. ${ }^{53}$ The conventional aspheric RGP designs provide a certain degree of myopic defocus for the peripheral tangential focal length, but almost no effect on the peripheral sagittal foci. This is in agreement with the results of Shen et al. ${ }^{17}$ Then, the peripheral myopic defocus would be negligible from the perspective of myopia control treatments. This partly agrees with the absence of effect of conventional (excepting orthokeratology) RGP lenses on myopia progression as previously reported in two different clinical trials. ${ }^{54,55}$

Biofinity and Proclear MFCL with +2.00 add powers showed minimal effect on myopic peripheral defocus induced. However, it has been observed that center-distance aspheric MFCL presents increasing peripheral myopic defocus as the peripheral add power increases, ${ }^{27}$ and higher add powers would be expected to induce more myopic defocus. Conversely, the Proclear with +3.00 add power induced a higher level of relative peripheral myopic defocus. In light of the potential effect of relative peripheral myopic defocus on myopia regulation, we could argue that a +3.00 add might be more effective than a +2.00 add center-distance aspheric multifocal contact lens. This is in agreement with the limited results in myopia retention found by Walline et al. in a clinical trial involving the use of Proclear multifocal with add $+2.00 \mathrm{D}^{23}$ The level of peripheral myopia is probably not the only factor involved in the peripheral induction of defocus. Evidence of the OK myopia retention effect can be seen in $\mathrm{Cho}^{21}$, and was expected to be almost $2 \mathrm{D}$, and in Kakita $^{22}$ almost 2.50 D of peripheral myopia induction was found. ${ }^{24}$ Nevertheless, the optimal results for induction of peripheral myopic defocus, peripheral $\mathrm{F}_{\mathrm{T}}$, and $\mathrm{F}_{\mathrm{S}}$ were seen with the CRT OK lens, experimental RGP lens, and wMFCL Proclear $+3.00 \mathrm{D}$ add (Table 4).

Beyond the amount of peripheral myopic defocus induced, the asymmetry between the nasal and temporal visual fields is evident for some treatments (center-distance multifocal contact lens) while others show a fairly symmetric effect (orthokeratology, experimental RGP). These effects might be relevant to the efficacy of myopia control considering the asymmetries shown between the nasal and retinal 
anatomy of progressive and non-progressive myopes. ${ }^{6} \mathrm{We}$ might also hypothesize that the degree of efficacy in myopia control of these treatments could be enhanced if personal approaches that could account for inter-subject variation and asymmetry in the peripheral refraction patterns were considered. Again, though some authors have found in prospective clinical trials that the sign of peripheral defocus does not predict the axial elongation of the eye during myopia development, those studies analyzed only the spherical equivalent components rather than the astigmatic defocus. ${ }^{7,56}$ Furthermore, the fact that the sign of peripheral defocus does not predict myopic progression does not directly imply that addressing treatments based on changing the peripheral defocus cannot be effective for myopia control. Indeed, several animal studies and clinical trials in humans seem to point towards the efficacy of such treatments. While the ultimate causative factors are still to be clarified, the potential role of peripheral defocus treatments cannot be ruled out, but considered carefully either per se or in association with other potential mechanisms.

In summary, in a young university Caucasian population, the present results may provide some clarification on the potential role of different devices in interfering with myopia progression based on the impact of relative peripheral myopic defocus and the potential role of astigmatism in acting as a critical cue for this mechanism.

\section{Acknowledgment}

The authors thank the companies that donated the contact lenses used in the study.

\section{Funding}

This study was supported by Fundação para Ciência e Tecnologia, Portugal through projects PTDC/SAU-BEB/098392/2008 and PTDC/ SAU-BEB/098391/2008.

\section{Declaration of interest}

The authors declare that they do not have any proprietary or financial interest in any of the materials mentioned in this article.

\section{ORCID}

António Queirós (D) http://orcid.org/0000-0003-1045-4455

Jose González-Méijome (D) http://orcid.org/0000-0001-9050-4170

\section{References}

1. Charman WN, Radhakrishnan H. Peripheral refraction and the development of refractive error: a review. Ophthalmic Physiol Opt 2010;30:321-338.

2. Wallman J, Winawer J. Homeostasis of eye growth and the question of myopia. Neuron 2004;43:447-468.

3. Smith EL III, Hung LF, Huang J. Relative peripheral hyperopic defocus alters central refractive development in infant monkeys. Vision Res 2009;49:2386-2392.

4. Atchison DA, Pritchard N, Schmid KL. Peripheral refraction along the horizontal and vertical visual fields in myopia. Vision Res 2006;46:1450-1458.
5. Kang P, Gifford P, McNamara P, Wu J, Yeo S, Vong B, Swarbrick H. Peripheral refraction in different ethnicities. Invest Ophthalmol Vis Sci 2010;51:6059-6065.

6. Faria-Ribeiro M, Queiros A, Lopes-Ferreira D, Jorge J, GonzalezMeijome JM. Peripheral refraction and retinal contour in stable and progressive myopia. Optom Vis Sci 2013;90:9-15.

7. Mutti DO, Sinnott LT, Mitchell GL, Jones-Jordan LA, Moeschberger ML, Cotter SA, et al. Relative peripheral refractive error and the risk of onset and progression of myopia in children. Invest Ophthalmol Vis Sci 2011;52:199-205.

8. Mutti DO, Mitchell GL, Hayes JR, Jones LA, Moeschberger ML, Cotter SA, et al. Accommodative lag before and after the onset of myopia. Invest Ophthalmol Vis Sci 2006;47:837-846.

9. Gwiazda J, Hyman L, Hussein M, Everett D, Norton TT, Kurtz D, et al. A randomized clinical trial of progressive addition lenses versus single vision lenses on the progression of myopia in children. Invest Ophthalmol Vis Sci 2003;44:1492-1500.

10. Hoogerheide J, Rempt F, Hoogenboom WP. Acquired myopia in young pilots. Ophthalmologica 1971;163:209-215.

11. Thibos LN, Bradley A, Liu T, Lopez-Gil N. Spherical aberration and the sign of defocus. Optom Vis Sci 2013;90:1284-1291.

12. Charman WN. Myopia, posture and the visual environment. Ophthalmic Physiol Opt 2011;31:494-501.

13. Anstice NS, Phillips JR. Effect of dual-focus soft contact lens wear on axial myopia progression in children. Ophthalmology 2011;118:1152-1161.

14. Sankaridurg P, Holden B, Smith E III, Naduvilath T, Chen X, de la Jara PL, et al. Decrease in rate of myopia progression with a contact lens designed to reduce relative peripheral hyperopia: one-year results. Invest Ophthalmol Vis Sci 2011;52:9362-9367.

15. Aller TA, Wildsoet C. Bifocal soft contact lenses as a possible myopia control treatment: a case report involving identical twins. Clin Exp Optom 2008;91:394-399.

16. Walline JJ, Lindsley K, Vedula SS, Cotter SA, Mutti DO, Twelker JD. Interventions to slow progression of myopia in children. Cochrane Database Syst Rev 2011;Dec 7;(12):CD004916.

17. Shen J, Clark CA, Soni PS, Thibos LN. Peripheral refraction with and without contact lens correction. Optom Vis Sci 2010;87:642-655.

18. Kang P, Fan Y, Oh K, Trac K, Zhang F, Swarbrick H. Effect of single vision soft contact lenses on peripheral refraction. Optom Vis Sci 2012;89:1014-1021.

19. Gonzalez-Meijome JM, Peixoto-de-Matos SC, Faria-Ribeiro M, Lopes-Ferreira DP, Jorge J, Legerton J, Queirós A. Strategies to regulate myopia progression with contact lenses: a review. Eye Contact Lens 2016;42(1):24-34.

20. Walline JJ, Jones LA, Sinnott LT. Corneal reshaping and myopia progression. Br J Ophthalmol 2009;93:1181-1185.

21. Cho P, Cheung SW, Edwards M. The longitudinal orthokeratology research in children (LORIC) in Hong Kong: a pilot study on refractive changes and myopic control. Curr Eye Res 2005;30:71-80.

22. Kakita T, Hiraoka T, Oshika T. Influence of overnight orthokeratology on axial elongation in childhood myopia. Invest Ophthalmol Vis Sci 2011;52:2170-2174.

23. Walline JJ, Greiner KL, McVey ME, Jones-Jordan LA. Multifocal contact lens myopia control. Optom Vis Sci 2013;90:1207-1214.

24. Queiros A, Gonzalez-Meijome JM, Jorge J, Villa-Collar C, Gutierrez AR. Peripheral refraction in myopic patients after orthokeratology. Optom Vis Sci 2010;87:323-329.

25. Mathur A, Atchison DA. Effect of orthokeratology on peripheral aberrations of the eye. Optom Vis Sci 2009;86:E476-E484.

26. Ticak A, Walline JJ. Peripheral optics with bifocal soft and corneal reshaping contact lenses. Optom Vis Sci 2013;90:3-8.

27. Lopes-Ferreira D, Ribeiro C, Maia R, García-Porta N, Queirós A, César Villa-Collar, et al. Peripheral myopization using a dominant design multifocal contact lens. J Optom 2011;4:14-21.

28. Lopes-Ferreira D, Ribeiro C, Neves H, Faria-Ribeiro M, Queirós A, César Villa-Collar, et al. Peripheral refraction with dominant design multifocal contact lenses in young myopes. J Optom 2013;6:85-94. 
29. Flitcroft DI. The complex interactions of retinal, optical and environmental factors in myopia aetiology. Prog Retin Eye Res 2012;31:622-660.

30. Ogata D, Weymouth FW. Refraction differences in foveal and parafoveal vision. Am J Ophthalmol 1918;1:630-644.

31. Ferree CE, Rand GG, Hardy CC. Refraction for the peripheral field of vision. Arch Ophthalmol 1931;5:717-731.

32. Koomen M, Scolnik R, Tousey R. A study of night myopia. J Opt Soc Am 1951;41:80-83.

33. Smith EL III, Hung LF. The role of optical defocus in regulating refractive development in infant monkeys. Vision Res 1999;39:1415-1435.

34. Kang P, Swarbrick H. Peripheral refraction in myopic children wearing orthokeratology and gas-permeable lenses. Optom Vis Sci 2011;88:476-482.

35. Kang P, Fan Y, Oh K, Trac K, Zhang F, Swarbrick HA. The effect of multifocal soft contact lenses on peripheral refraction. Optom Vis Sci 2013;90:658-666.

36. Kwok E, Patel B, Backhouse S, Phillips JR. Peripheral refraction in high myopia with spherical soft contact lenses. Optom Vis Sci 2012;89:263-270

37. Lin Z, Martinez A, Chen X, Li L, Sankaridurg P, Holden BA, Ge J, et al. Peripheral defocus with single-vision spectacle lenses in myopic children. Optom Vis Sci 2010;87:4-9.

38. Sankaridurg P, Donovan L, Varnas S, Ho A, Chen X, Martinez A, et al. Spectacle lenses designed to reduce progression of myopia: 12-month results. Optom Vis Sci 2010;87:631-641.

39. Mathur A, Atchison DA, Charman WN. Effect of accommodation on peripheral ocular aberrations. J Vis 2009;9:20-11.

40. Paune J, Queiros A, Quevedo L, Neves H, Lopes-Ferreira D, Gonzalez-Meijome JM. Peripheral myopization and visual performance with experimental rigid gas-permeable and soft contact lens design. Cont Lens Anterior Eye 2014;37:455-460.

41. Paune J, Queiros A, Lopes-Ferreira D, Faria-Ribeiro M, Quevedo L, Gonzalez-Meijome JM. Efficacy of a gas-permeable contact lens to induce peripheral myopic defocus. Optom Vis Sci 2015;92:596-603.

42. Lopes-Ferreira DP, Neves HI, Faria-Ribeiro M, Queiros A, Fernandes PR, Gonzalez-Meijome JM. Peripheral refraction with eye and head rotation with contact lenses. Cont Lens Anterior Eye 2015;38:104-109.

43. Queiros A, Gonzalez-Meijome J, Jorge J. Influence of fogging lenses and cycloplegia on open-field automatic refraction. Ophthalmic Physiol Opt 2008;28:387-392.

44. Thibos LN, Wheeler W, Horner D. Power vectors: an application of Fourier analysis to the description and statistical analysis of refractive error. Optom Vis Sci 1997;74:367-375.
45. Gonzalez-Meijome JM, Faria-Ribeiro M, Lopes-Ferreira D, Fernandes P, Carracedo G, Queiros A. Changes in peripheral refractive profile after orthokeratology for different degrees of myopia. Curr Eye Res 2016;41(2):199-207.

46. Smith EL III, Kee CS, Ramamirtham R, Qiao-Grider Y, Hung LF. Peripheral vision can influence eye growth and refractive development in infant monkeys. Invest Ophthalmol Vis Sci 2005;46:3965-3972.

47. Kee CS, Hung LF, Qiao-Grider Y, Roorda A, Smith EL III. Effects of optically imposed astigmatism on emmetropization in infant monkeys. Invest Ophthalmol Vis Sci 2004;45:1647-1659.

48. Hung LF, Ramamirtham R, Huang J, Qiao-Grider Y, Smith EL III. Peripheral refraction in normal infant rhesus monkeys. Invest Ophthalmol Vis Sci 2008;49:3747-3757.

49. Smith EL III, Greeman N, Ho A, Holden BA. Methods and apparatuses for altering relative curvature of field and positions of visual extent of the peripheral off-axis focal positions. US Patent 7.025.460 B2; 2006.

50. Paune J, Thivent S, Armengol J, Quevedo L, Faria-Ribeiro M, Gonzalez-Meijome JM. Changes in peripheral refraction, higher order aberrations, and accommodative lag with a radial refractive gradient contact lens in young myopes. Eye Contact Lens in press.

51. Gonzalez-Meijome JM, Carracedo G, Lopes-Ferreira D, FariaRibeiro MA, Peixoto-de-Matos SC, Queiros A. Stabilization in early adult-onset myopia with corneal refractive therapy. Cont Lens Anterior Eye 2015; Jul 15.pii: S1367-0484(15)30010-2.

52. Paune J, Morales H, Armengol J, Quevedo L, Faria-Ribeiro M, Gonzalez-Meijome JM. Myopia control with a novel peripheral gradiente soft lens and orthokeratology: a 2-year clinical trial. Biomed Res Int 2015;2015:507572.

53. Smith EL III. Optical treatment strategies to slow myopia progression: effects of the visual extent of the optical treatment zone. Exp Eye Res 2013;114:77-88.

54. Walline JJ, Jones LA, Mutti DO, Zadnik K. A randomized trial of the effects of rigid contact lenses on myopia progression. Arch Ophthalmol 2004;122:1760-1766.

55. Katz J, Schein OD, Levy B, Cruiscullo T, Saw SM, Rajan U, et al. A randomized trial of rigid gas-permeable contact lenses to reduce progression of children's myopia. Am J Ophthalmol 2003;136:82-90.

56. Atchison DA, Li SM, Li H, Li SY, Liu LR, Kang MT, et al. Relative peripheral hyperopia does not predict development and progression of myopia in children. Invest Ophthalmol Vis Sci 2015;56:6162-6170. 